\title{
MORTALIDADE DE ADULTOS JOVENS POR CAUSAS EXTERNAS NO MUNICÍPIO DE IMPERATRIZ - MA, NO BIÊNIO (2017 - 2018)
}

\section{ARTIGO ORIGINAL}

NOGUEIRA, Carlos Alberto de Sousa ${ }^{1}$

BRANDÃO, Fernando Barbosa ${ }^{2}$

NOGUEIRA, Carlos Alberto de Sousa. BRANDÃO, Fernando Barbosa. Mortalidade de adultos jovens por causas externas no Município de Imperatriz - MA, no biênio (2017 - 2018). Revista Científica Multidisciplinar Núcleo do Conhecimento. Ano 05, Ed. 09, Vol. 05, pp. 31-58. Setembro de 2020. ISSN: 2448-0959, Link de acesso: https://www.nucleodoconhecimento.com.br/saude/mortalidade-de-adultos

\section{RESUMO}

A mortalidade por causas externas têm-se destacado nos dias atuais devido ao número de casos registrados e suas consequências na sociedade. No caso do Brasil, os adultos jovens de 20 a 39 anos, do sexo masculino, são o grupo mais atingido por essas causas. Estudos locais que procurem abordar as consequências das causas externas de óbitos na população juvenil masculina, podem contribuir sobremaneira para ações no sentido de reduzir os elevados números atuais. O objetivo do presente estudo foi identificar os diferenciais da mortalidade de adultos jovens, por causas externas, no município de Imperatriz - MA, no biênio (2017 e 2018). O trabalho consistiu de um estudo documental retrospectivo, descritivo, com abordagem quantitativa, realizado no município de Imperatriz - MA, utilizando a base de dados do

${ }^{1}$ Acadêmico do 8o período do curso de Medicina.

${ }^{2}$ Orientador. Doutorado em Clínicas odontológicas. Mestrado em Ciências da Saúde. Especialização em andamento em Curso de especialização em endodontia. Especialização em Radiologia odontológica e imaginologia. Graduação em Odontologia. 
Instituto Médico Legal (IML). A amostragem consistiu das ocorrências que deram entrada na referida instituição nos anos de 2017 e 2018, por meio da avaliação dos laudos cadavéricos e declarações de óbito. As variáveis utilizadas foram a causa do óbito, idade, gênero, grau de escolaridade, etnia e estado civil. As estimativas populacionais foram obtidas a partir dos dados censitários do Instituto Brasileiro de Geografia e Estatística (IBGE). As taxas de mortalidade (TM) foram calculadas por 100.000 habitantes de acordo com a causa específica. Pelo presente trabalho foi possível concluir que a taxa de mortalidade no município foi elevada, superior à média brasileira nos dois anos estudados, sendo as principais causas externas, os projéteis de arma de fogo, seguidos pelos acidentes de trânsito e agressão por instrumento perfurocortante. As principais vítimas de causas externas foram adultos jovens, do sexo masculino com baixo grau de escolaridade, pardos e solteiros.

Palavras-chave: causas externas, taxa de mortalidade, adultos jovens.

\section{INTRODUÇÃO}

A mortalidade por causas externas tem-se destacado nos dias atuais devido ao número de casos registrados e suas consequências na sociedade. Desse modo, tornou-se um problema de saúde pública, por atingir a maioria da população jovem em idade produtiva, com consequências graves que envolvem altos custos sociais, emocionais e econômicos para o tratamento e reabilitação, além de trazer danos incalculáveis para a vítima e as famílias (SOUSA et al., 2016).

As causas externas podem ser definidas como lesões, traumatismo ou quaisquer outros danos à saúde, intencionais ou não, de início súbito e como consequência imediata de violência ou outra causa exógena, incluindo as lesões provocadas no trânsito e transporte, homicídios, agressões, suicídios, quedas, afogamentos, envenenamentos, queimaduras, lesões por deslizamento ou enchente, e outras ocorrências provocadas por desastres ambientais, sejam elas mecânica, química, térmica, energia elétrica e/ou radiação (OLIVEIRA et al., 2019; SETTERVALL et al., 2012). 
Os dados da Organização Mundial de Saúde (OMS) demonstram que acidentes e violência são as causas de mais de 5 milhões de mortes anuais, representando aproximadamente $9 \%$ da mortalidade global. A estimativa é que $16 \%$ dessas mortes resultem de suicídios, 10\%, de homicídios, 24\%, de acidentes de trânsito, $14 \%$, de quedas, com o restante distribuído entre outras causas (CORASSA et al., 2017). Para cada morte, estimam-se dezenas de hospitalizações, centenas de visitas a unidades de pronto atendimento e milhares de consultas médicas (COSTA et al., 2013).

Os óbitos por causas externas no Brasil, desde a década 1980, correspondem a segunda causa de morte, superados somente pelas doenças do aparelho circulatório (GONSAGA et al., 2012; TREVISOL et al., 2011).

A violência e os acidentes que são um grupo significativo de causas externas, são constituídas pelos acidentes de trânsito, homicídios, suicídios, intoxicações, acidentes de trabalho, queimaduras, quedas, afogamentos, constituem importantes fatores de morbidade e mortalidade de adultos jovens (SILVA et al., 2010).

No Brasil, os homicídios não estão mais concentrados somente nas grandes cidades, difundindo-se de forma mais generalizada nas últimas décadas, afetando também as cidades de médio porte do interior (COSTA, et al., 2014).

O crescimento da mortalidade por causas externas no Brasil ocorreu, principalmente, a partir da década de 1980, passando do quarto para o segundo lugar no ordenamento dos grupos de causas de óbitos, entre o início e o final daquela década (TRISTÃO et al., 2012).

As causas externas não afetam a população de maneira uniforme. Diversos estudos demonstraram que existem grupos populacionais mais predispostos, o que pode ser percebido pela distribuição desigual das mortes por causas externas (LIMA et al., 2013).

Em relação às causas associadas às mortes violentas ainda não existe consenso. Fatores biológicos e multicausais estão envolvidos: fatores socioeconômicos; a constituição familiar; o ambiente doméstico; a idade e as características de 
personalidade; o sexo da vítima; a etnia da vítima; o uso de bebidas alcoólicas e de substâncias químicas (AMADOR et al., 2018).

No caso do Brasil, os adultos jovens de 20 a 39 anos, do sexo masculino, são o grupo mais atingido pelas causas externas, e estas são consideradas como as maiores responsáveis pelos anos potenciais perdidos. Na maioria das vezes as ocorrências são fatais, como consequência, a mortalidade masculina é cinco vezes maior que a feminina, na faixa etária de 20 a 25 anos (IBGE, 2009).

A partir da fase da adolescência o comportamento adotado pela maioria dos jovens, torna-os mais expostos e vulneráveis aos riscos de serem vítimas de violência (CAVALCANTE; MONTEIRO, 2008). A violência está entre as principais causas de mortalidade no país (WAISELFISZ, 2013).

O conhecimento sobre os óbitos por causas externas fornece subsídios para a implementação de ações de prevenção e elaboração de estratégias de enfrentamento abrangentes. Por esse motivo, é importante mencionar que o brasil apresenta ampla extensão territorial e uma grande diversidade cultural, demográfica e socioeconômica, o que justifica a necessidade de identificação dos contrastes regionais que afetam na vida e saúde da população, subsidiando o planejamento e a tomada de decisão sobre ações direcionadas aos grupos de maior risco (PREIS et al., 2018).

O elevado número de óbitos e sequelas/incapacidades, ocasionadas pelas causas externas, constituem importante demanda para que políticas públicas de segurança e saúde sejam elaboradas, implementadas e seguidas no Brasil (BATISTA et al., 2018).

O Ministério da Saúde lançou, em 2001, a Política Nacional de Redução de Morbimortalidade de Acidentes e Violências (PNRMAV), aprovada pela portaria $n^{-}$ 737/GM em 16 de maio de 2001, onde destaca a importância e o papel do setor saúde no enfrentamento dos acidentes e violência no país, mediante o desenvolvimento de um conjunto de ações articuladas e sistematizadas, em conformidade com as diretrizes da PNRMAV (MATOS; MARTIGNS, 2013). 
Estudo realizado no estado do Maranhão, no período de 2001 a 2010, demonstrou aumento dos óbitos em todas as faixas etárias, com destaque para faixa entre 20-35 anos, que variou de 6,1\% em 2001 para 15,6\% em 2010 (LIMA et al., 2013). No entanto, o estado ainda carece de estudos mais detalhados sobre as causas externas de óbitos.

Os estudos realizados no estado apresentam caráter mais geral, não havendo avaliações mais precisas da realidade nos seus municípios. Por esse motivo, o presente trabalho tem por objetivo identificar os diferenciais da mortalidade de adultos jovens, por causas externas, no município de Imperatriz - MA, no biênio (2017 e 2018).

\section{OBJETIVOS}

\subsection{OBJETIVO GERAL}

Identificar os diferenciais da mortalidade de adultos jovens, por causas externas, no município de Imperatriz - MA, no biênio (2017 e 2018).

\subsection{OBJETIVOS ESPECÍFICOS}

- Determinar as taxas de mortalidade geral e por grupo de causa externa e fazer a comparação dos grupos entre si.

- Classificar o quantitativo total de vítimas em grupos, de acordo com a causa de óbito, identificada pela avaliação de legista.

- Identificar, quantificar e classificar, por grupo etário, as principais causas externas de óbitos, no período avaliado.

- Comparar as vítimas das causas externas de óbitos, do grupo dos adultos jovens, em relação ao gênero, grau de escolaridade, etnia e estado civil. 


\section{METODOLOGIA}

\section{1 ÁREA DE ESTUDO}

O estudo foi realizado no município de Imperatriz, localizado no sudoeste do Estado do Maranhão, na microrregião de Imperatriz. Concentra a segunda maior população do estado, totalizando 258.016 habitantes dos quais $48,16 \%$ são do sexo masculino e $52,84 \%$ do sexo feminino, segundo estimativa do Instituto Brasileiro de Geografia e Estatística (IBGE) para o ano de 2018 (IBGE, 2018) e área de 1.367,901 km², dos quais $15,480 \mathrm{~km}^{2}$ correspondem à zona urbana.

A cidade se estende pela margem direita do rio Tocantins e é atravessada pela Rodovia Belém-Brasília (BR-010). É o maior entroncamento comercial, energético e econômico do Maranhão e possui um posicionamento geográfico estratégico não só ao estado, mas também para todo o norte do país.

A maior parte da mão-de-obra ativa do município é absorvida pelo setor terciário (comércio de mercadorias e prestação de serviços). A construção civil também desempenha papel muito importante na economia local. Mais recentemente, a atividade industrial ganhou expressão com a instalação de indústria de grande porte, atraindo outras empresas associadas e este empreendimento.

\subsection{TIPO DE ESTUDO}

O trabalho consistiu de um estudo documental retrospectivo, descritivo, com abordagem quantitativa, realizado no município de Imperatriz - MA, utilizando a base de dados do Instituto Médico Legal (IML), local para onde são encaminhadas as vítimas de mortes por causas externas para realização de procedimentos Legais e necropsia.

\subsection{AMOSTRA E COLETA DOS DADOS}

A amostragem foi composta pelas ocorrências que deram entrada no Instituto Médico Legal (IML) de Imperatriz, no período de janeiro de 2017 a dezembro de 2018, por 
meio da avaliação dos laudos cadavéricos e declarações de óbito. Os dados utilizados foram a causa do óbito, idade, gênero, grau de escolaridade, etnia e estado civil.

As causas externas foram classificadas de acordo com o Capítulo XX da 10 Classificação Internacional de Doenças - CID10: os acidentes estão contidos nos capítulos V01-Y98 em que os acidentes de transporte estão nas categorias V01- V99 e outras causas externas de lesões acidentais W00-X59.

Consideraram-se homicídios as lesões provocadas intencionalmente, classificadas pela CID-10, como "Agressões" (X85 a Y09) e ainda as "Intervenções Legais" (Y35 a Y36): incluem agressões por arma de fogo (AAF) (X93-X95), agressões por instrumento perfurocortante (AIP) (X99) e outras violências. Em intervenções legais (Y35) são incluídos traumatismos infligidos pela polícia ou outros agentes da lei, incluindo militares em serviço, durante a prisão ou tentativa de prisão de transgressores da lei, ao reprimir tumultos, ao manter a ordem ou outra ação legal. Os suicídios/lesões autoprovocadas intencionalmente estão em X60-X84.

\subsection{CRITÉRIOS DE INCLUSÃO E EXCLUSÃO}

Os critérios de inclusão do estudo foram: (1) laudos cadavéricos e declarações de óbito referentes às necropsias realizadas no período de janeiro de 2017 a dezembro de 2018; (2) laudos cadavéricos e declarações de óbitos de indivíduos que residiam no município de Imperatriz - MA; (3) óbitos declarados como causas externas.

Os critérios de exclusão foram: (1) laudos cadavéricos e declarações de óbito anteriores a janeiro de 2017 e posteriores a dezembro de 2018; (2) laudos cadavéricos e declarações de óbitos de indivíduos que não residiam no município de Imperatriz MA; (3) óbitos não-declarados como causas externas; (4) indivíduos não-identificados em declaração de óbito.

\subsection{ASPECTOS ÉTICOS}

Por se tratar da utilização de dados secundários obtidos de um banco de dados (IML) é necessária a dispensa do TERMO DE CONSENTIMENTO LIVRE E ESCLARECIDO 
para realização deste projeto, pois os pesquisadores terão acesso somente dados de necropsias.

Foram garantidos os direitos, dentre outros assegurados pela resolução 466/2012 do Conselho Nacional de Saúde:

1) Garantia da confidencialidade, do anonimato e da não utilização das informações em prejuízo dos outros;

2) Que não haverá riscos para o sujeito de pesquisa;

3) Emprego dos dados somente para fins previstos nesta pesquisa;

4) Retorno dos benefícios obtidos através deste estudo para as pessoas e a comunidade onde o mesmo foi realizado.

A pesquisa somente será iniciada após a aprovação do Comitê de Ética em Pesquisa - CEP, para garantir a todos os envolvidos os referenciais básicos da bioética, isto é, autonomia, não maleficência, benevolência e justiça.

\subsection{ANÁLISE DE DADOS}

As estimativas populacionais foram obtidas a partir dos dados censitários do Instituto Brasileiro de Geografia e Estatística (IBGE). As taxas de mortalidade (TM), geral e pelas diferentes causas externas, foram calculadas por 100.000 habitantes conforme a fórmula:

$\mathrm{TM}=(\mathrm{n}$ o de óbitos por grupo de causa/população estimada $) \times 100.000$

Os resultados obtidos com o uso da fórmula acima, foram utilizados para comparar a taxa geral de mortalidade com resultados de estudos em outros municípios e comparar, entre si, as principais causas externas de óbitos no município pesquisado. 
Tabela 1 - Dados organizados para análise estatística.

\begin{tabular}{|c|c|c|c|c|c|c|c|c|c|c|}
\hline AN & CAUS & & & & & & & & & \\
\hline 0 & $\begin{array}{l}\text { Ac. } \\
\text { trâns } \\
\text { ito }\end{array}$ & $\begin{array}{l}\text { Afogame } \\
\text { nto }\end{array}$ & $\begin{array}{l}\text { Choq } \\
\text { ue } \\
\text { elétri } \\
\text { co }\end{array}$ & $\begin{array}{l}\mathrm{Al} \\
\mathrm{P}\end{array}$ & $\begin{array}{l}\mathrm{AA} \\
\mathrm{F}\end{array}$ & $\begin{array}{l}\text { Suicí } \\
\text { dio }\end{array}$ & $\begin{array}{l}\text { Queimad } \\
\text { ura }\end{array}$ & $\begin{array}{l}\text { Qued } \\
\text { as }\end{array}$ & $\begin{array}{l}\text { Agress } \\
\text { ão } \\
\text { física }\end{array}$ & $\begin{array}{l}\text { outr } \\
\text { os }\end{array}$ \\
\hline $\begin{array}{l}20 \\
18\end{array}$ & 34 & 1 & 4 & 32 & $\begin{array}{l}10 \\
2\end{array}$ & 8 & 3 & 9 & 9 & 2 \\
\hline $\begin{array}{l}20 \\
17\end{array}$ & 56 & 7 & 10 & 18 & 73 & 14 & 1 & 13 & 5 & 2 \\
\hline
\end{tabular}

Fonte: resultado da pesquisa.

Os dados de mortalidade por grupo de causa foram analisados por meio do programa Biostat. Para análise estatística desses dados, foram necessárias transformações no conjunto de dados. Primeiramente, para haver repetição, os dados tiveram que ser analisados com os dois anos de referência (2017 e 2018), representando blocos. Os tratamentos consistiram das causas de mortalidade (acidente de trânsito, agressão por arma de fogo...) (Tabela 1).

Como os dados foram oriundos de contagem (variável discreta), foi necessário realizar uma transformação, usando para isso a relativização dos valores sobre o total anual, tornando a variável em contínua.Com a homogeneização e transformação dos dados, foi calculada a análise de variância dos dados, utilizando um DBC (delineamento em blocos casualisados), com a finalidade de responder a seguinte hipótese:

\section{$\begin{cases}H_{0} & \text { As médias não diferem entre si } \\ H_{1} & \text { As médias diferem entre si }\end{cases}$}


Para comparação das diferentes médias das causas de mortalidade, foi aplicado o teste Tukey a $95 \%$.

As variáveis grupo etário, gênero, grau de escolaridade, etnia e estado civil, foram subdivididas, individualmente, em classes e os dados transformados em porcentagem, para finalidade de comparação. Para a análise por gênero, grau de escolaridade, etnia e estado civil, utilizou-se somente dados do grupo classificado como adultos jovens, determinado na avaliação por grupo etário.

\section{RESULTADOS E DISCUSSÃO}

\subsection{MORTALIDADE GERAL E POR DIFERENTES CAUSAS}

A análise dos dados obtidos identificou que o número de óbitos por causas externas no município de Imperatriz - MA, foi de 199 e 204, respectivamente nos anos de 2017 e 2018.

As taxas de mortalidade por causas externas no município de Imperatriz - MA, nos anos de 2017 e 2018 foram, respectivamente, de 80,4 e 82,42 óbitos por 100 mil habitantes, demonstrando que apresentaram valores próximos nos dois anos estudados. Esses resultados indicam a relevância dessas causas de óbitos sobre a mortalidade geral da população estudada.

A taxa de mortalidade por causas externas no Brasil, em 2014, foi de 75,5 óbitos por 100 mil habitantes, variando de 26,4 óbitos por 100 mil mulheres a 125,5 óbitos por 100 mil homens (BRASIL, 2015). No Brasil, as causas externas representam a primeira posição na população de adultos jovens e ocupam a terceira posição entre a população acima de 50 anos (BRASIL, 2017).

No município de Diamantina - MG, uma avaliação sobre as causas externas de mortalidade identificou, no período de 2001 a 2012, um total de 233 óbitos por essas causas (7,6\% do total), com um coeficiente de mortalidade médio anual de 44,3/100 mil habitantes (CORASSA et al., 2017), valor bem abaixo do encontrado nos dois anos do presente estudo. 
Os resultados obtidos no presente estudo comprovaram que a taxa de mortalidade por causas externas no município de Imperatriz - MA, nos dois anos avaliados, pode ser considerada elevada, por apresentar taxas superiores à média brasileira e de outras cidades onde estudos semelhantes foram realizados.

A avaliação das taxas de mortalidade pelas diferentes causas externas identificadas, demonstrou que as três principais foram, respectivamente: 1) agressão por arma de fogo; 2) acidente de trânsito e 3) agressão por instrumento perfurocortante (Tabela 2).

Tabela 2 - Taxas de mortalidade pelas diferentes causas externas, no município de Imperatriz - MA, nos anos de 2017 e 2018.

\begin{tabular}{|l|l|l|}
\hline CAUSAS & TM 2017 & TM 2018 \\
\hline Agressão por arma de fogo & 29,49 & 41,21 \\
\hline $\begin{array}{l}\text { Acidente de trânsito } \\
\text { Agressão por instrumento } \\
\text { perfurocortante }\end{array}$ & 22,63 & 13,74 \\
\hline $\begin{array}{l}\text { Suicídio } \\
\text { Quedas }\end{array}$ & 12,93 \\
\hline Choque elétrico & 5,66 & 3,23 \\
\hline Afogamento & 5,25 & 3,64 \\
\hline Agressão física & 4,04 & 1,62 \\
\hline Queimadura & 2,83 & 0,40 \\
\hline Outros & 2,02 & 3,64 \\
\hline TOTAL & 0,40 & 1,21 \\
\hline
\end{tabular}

Fonte: resultado da pesquisa.

Do ano de 2017 para 2018, a taxa de mortalidade por agressão por arma de fogo aumentou de 29,49 para 41,21. Por acidente de trânsito, reduziu de 22,63 para 13,74. Por agressão por instrumento perfurocortante aumentou de 7,27 para 12,93. Esses resultados são semelhantes aos obtidos em estudos anteriores realizados em outras 
cidades, os quais também identificaram o uso de armas de fogo e acidentes de trânsito como as duas principais causas externas de óbitos em suas populações.

No estado do Maranhão, no período de 2001 a 2010, observou-se que as agressões de diversos tipos (35,5\%) seguidas por ocupante de veículo traumatizado $(16,6 \%)$, foram as duas maiores causas externas de óbitos (LIMA et al., 2013).

$\mathrm{Na}$ região nordeste, em média, $30 \%$ das mortes por causas externas foram ocasionadas por acidentes de transporte terrestre (BRASIL, 2015).

Os acidentes de trânsito provocam altos índices de mortalidade e morbidade, acarretando desta forma impactos sociais para os indivíduos, sua família e sociedade como um todo, associado ainda a altos custos para o sistema de saúde (GONSAGA et al., 2012).

Com relação às causas externas de óbitos, por meio da análise de variância, ficou evidente que não existe diferença estatística do somatório de óbitos, entre os anos de 2017 e 2018 (aceita-se Ho) (Tabela 3). No entanto, foi verificada diferença altamente significativa entre as causas da mortalidade (rejeita-se $\mathrm{H}_{0}$ ).

Tabela 3 - Análise de variância das causas externas de mortalidade nos anos de 2017 e 2018, no município de Imperatriz - MA.

\begin{tabular}{|l|l|l|l|l|l|}
\hline $\begin{array}{l}\text { Fonte } \\
\text { variação }\end{array}$ & SQ & gl & MQ & $\boldsymbol{F}$ & $\begin{array}{l}\text { F crítico } \\
\text { (95\%) }\end{array}$ \\
\hline $\begin{array}{l}\text { Linhas (anos) } \\
\text { Colunas }\end{array}$ & $-4,5 \mathrm{E}-13$ & 1 & $-4,5 \mathrm{E}-13$ & $-2,1 \mathrm{E}-14$ & 5,117355 \\
\hline (causas) & 3246,92 & 9 & 360,7689 & 16,63461 & 3,178893 \\
\hline $\begin{array}{l}\text { Erro } \\
\text { Total }\end{array}$ & 195,1906 & 9 & 21,68785 & & \\
\hline
\end{tabular}

Em que: SQ: soma de quadrados; gl: graus de liberdade; $M Q$ : quadrado médio; F: valor calculado; F crítico: valor de $\mathrm{F}$ tabelado $p>99 \%$ 
Fonte: resultado da pesquisa.

Para comparação das porcentagens das causas externas de mortalidade, foi aplicado o teste Tukey a 95\%. Os resultados do teste estão na tabela 4.

Tabela 4 - Comparação das porcentagens de mortalidade por causas externas pelo Teste Tukey a 95\%.

\begin{tabular}{|c|c|c|c|}
\hline Causa & $\begin{array}{l}\text { Média } \\
(\%)\end{array}$ & & \\
\hline Agressão por arma de fogo & 43,3 & $a^{*}$ & \\
\hline Acidente de trânsito & 22,4 & a & b \\
\hline Agressão por instrumento perfurocortante & 12,4 & & $\mathrm{~b}$ \\
\hline Suicídio & 5,5 & & $b$ \\
\hline Quedas & 5,5 & & $\mathrm{~b}$ \\
\hline Choque elétrico & 3,5 & & $\mathrm{~b}$ \\
\hline Agressão física & 3,5 & & $b$ \\
\hline Afogamento & 2,0 & & $\mathrm{~b}$ \\
\hline Queimadura & 1,0 & & $b$ \\
\hline Outros & 1,0 & & $b$ \\
\hline
\end{tabular}

*médias seguidas de mesma letra não diferem pelo teste Tukey a 95\%

Fonte: resultado da pesquisa.

O teste Tukey a 95\% demonstrou haver diferença estatisticamente significativa dos óbitos por projéteis de arma de fogo, quando comparados às demais causas, com exceção dos acidentes de trânsito, que foram a segunda maior causa externa de óbitos nos dois anos avaliados.

Os acidentes de trânsito e os homicídios ocasionados, principalmente, pelo uso de arma de fogo estão entre as principais causas de morte que contribuem para os altos índices de óbitos por causas externas (PALMEIRA et al., 2009), o que demonstra que os resultados encontrados são compatíveis com os obtidos em estudos anteriores. 
No Brasil, em média, $71 \%$ dos homicídios envolvem uso de armas de fogo, legais ou ilegais. Por serem altamente letais e normalmente de fácil acesso, quando associadas a uma sociedade violenta, potencializam o risco de que conflitos de ordem diversa terminem em mortes (AMADOR et al., 2018).

\section{2 ÓBITOS POR GRUPO ETÁRIO}

O grupo dos adultos jovens foi o que apresentou maior mortalidade por causas externas nos dois anos avaliados, correspondendo a 51,76 e 62,25\%, respectivamente para os anos de 2017 e 2018, evidenciando que no período avaliado, mais da metade dos óbitos por causas externas ocorreu com indivíduos nesse grupo etário (Figuras 1 e 2).

Figuras 1 e 2 - Percentuais de mortalidade por causas externas no município de Imperatriz - MA, segundo o grupo etário, nos anos de 2017 e 2018.
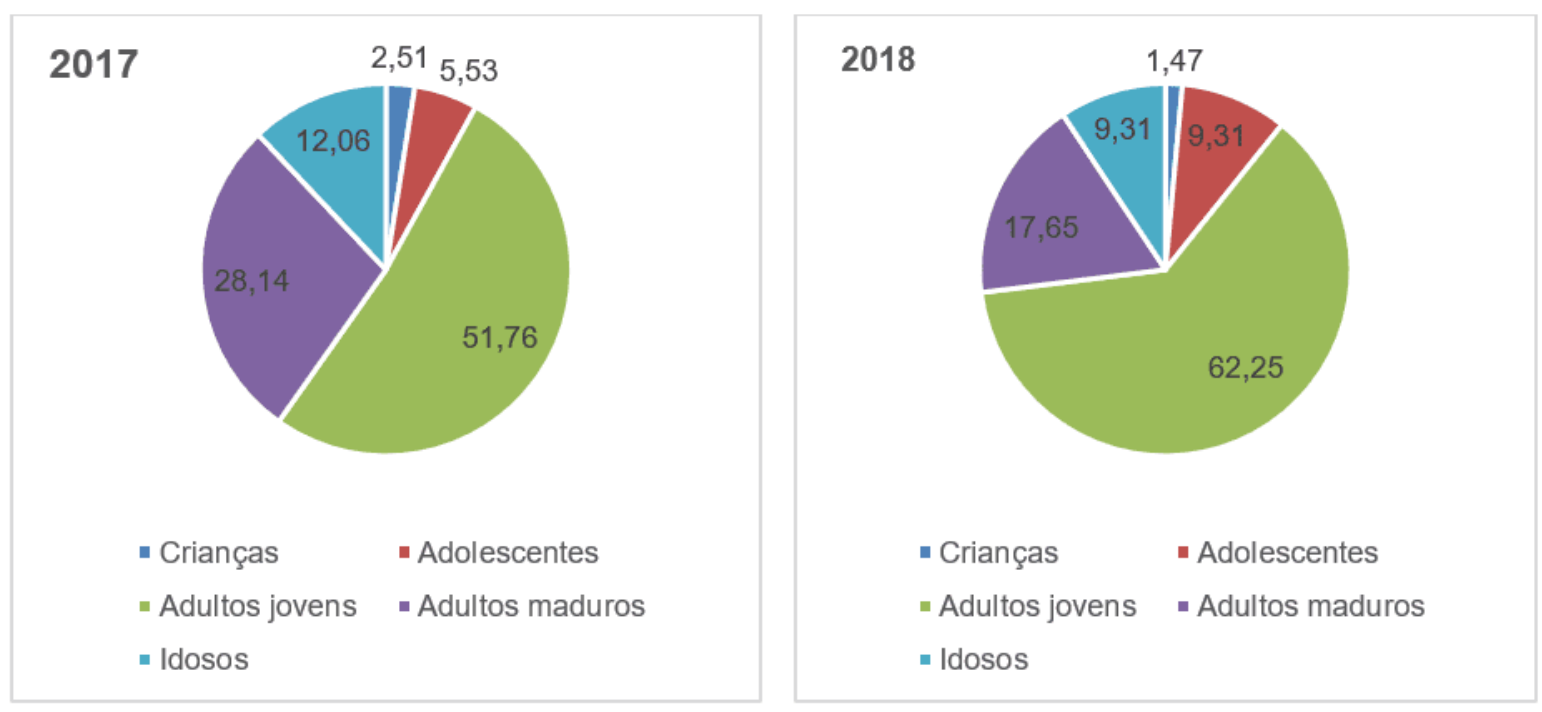

Fonte: resultado da pesquisa.

No período de 2001 a 2011, a maioria dos óbitos por causas externas em Teresina $\mathrm{PI}$, ocorreu na faixa etária de 20 a 29 anos (64,8\%) já na faixa etária de 30-39 anos a mortalidade por causas externas foi de 35,2 \% (SOUSA et al., 2016). Pesquisas apontam que a vulnerabilidade a causas externas das pessoas na faixa etária de 20 a 35 anos também está relacionada a determinados comportamentos de risco, como 
a busca de emoções, o prazer em experimentar situações de risco, a impulsividade e o abuso de substâncias psicoativas (SOUZA et al., 2007).

No ano de 2015, no Brasil, os homicídios corresponderam a 47,8\% do total de óbitos da população masculina, de 15 a 29 anos, trazendo implicações na saúde, na dinâmica demográfica e, por conseguinte, no processo de desenvolvimento econômico e social (AMADOR et al., 2018).

Os resultados obtidos no presente trabalho são corroborados por outros estudos, como os anteriormente mencionados, que também indicaram alto percentual de mortalidade por causas externas entre adultos jovens. Esses resultados demonstram o impacto das causas externas para o grupo dos adultos jovens, repercutindo diretamente na dinâmica de toda a sociedade, por se tratarem de pessoas que estão iniciando ou já estão no auge da idade produtiva intelectual e laboral.

Os dois grupos etários que apresentaram maiores taxas de mortalidade (TM) por causas externas nos anos de 2017 e 2018 foram: 1) adultos jovens; 2) adultos maduros (Tabela 5).

Tabela 5 - Taxas de mortalidade por causas externas, por grupo etário, no município de Imperatriz - MA, nos anos de 2017 e 2018.

\begin{tabular}{|l|l|l|}
\hline GRUPO ETÁRIO & TM 2017 & TM 2018 \\
\hline TM Crianças & 2,02 & 1,21 \\
\hline TM Adolescentes & 4,44 & 7,68 \\
\hline TM Adultos jovens & 41,62 & 51,31 \\
\hline TM Adultos maduros & 22,63 & 14,55 \\
\hline TM Idosos & 9,70 & 7,68 \\
\hline
\end{tabular}

Fonte: resultado da pesquisa.

Nos dois anos avaliados, a soma das taxas desses dois grupos foi superior a $60 \%$ do total dos óbitos ocorridos, demonstrando que são os principais grupos vitimados por causas externas no município, no biênio estudado. 


\section{3 ÓBITOS POR GÊNERO}

Nos dois anos avaliados, os indivíduos do sexo masculino representaram o maior número de óbitos por causas externas de adultos jovens, correspondendo a 86,93 e 88,24\%, respectivamente para os anos de 2017 e 2018 (Figuras 3 e 4), demonstrando que as causas externas atingem com uma frequência amplamente maior os homens, de modo semelhante a outros estudos que avaliaram óbitos por causas externas por gênero.

Figuras 3 e 4 - Percentuais de mortalidade de adultos jovens, por causas externas, segundo o gênero, no município de Imperatriz - MA, nos anos de 2017 e 2018.
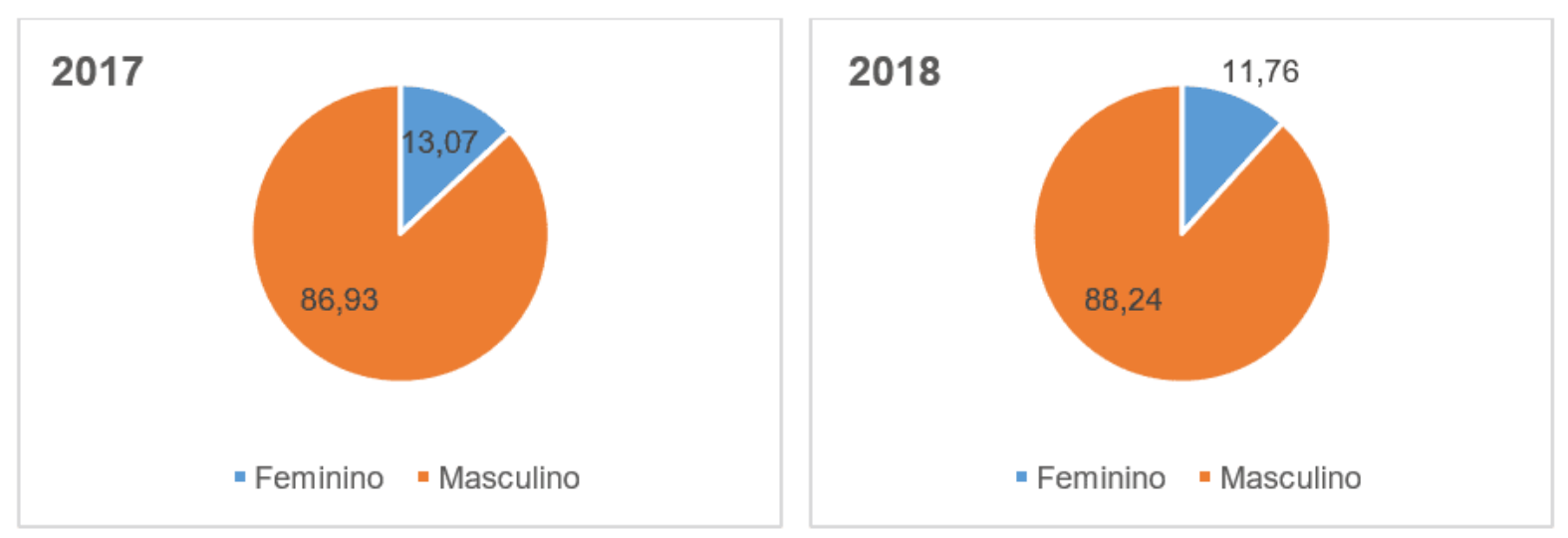

Fonte: resultado da pesquisa.

Os altos índices de mortalidade masculina por causas externas na faixa etária de 15 a 39 anos, têm contribuído para o aumento do diferencial de anos perdidos em comparação com o sexo feminino (DANTAS, 2014).

No ano de 2013, no Brasil, as causas externas foram responsáveis por 151.683 óbitos registrados no Sistema de Informações de Mortalidade (SIM), destes, a maior parte foram homens $(82,2 \%)$ e pessoas com idade de 20 a 39 anos $(43,8 \%)$. Em relação a raça/cor da pele, houve predomínio dos pardos $(50,1 \%)$, seguidos dos brancos $(37,3 \%)$ (BRASIL, 2015).

No ano de 2010, as causas externas foram a segunda causa de óbito entre os homens em 26 capitais brasileiras, sendo a cidade do Rio de Janeiro a única capital a registrar 
este grupo como a terceira causa de morte (DANTAS, 2014). A taxa média de mortalidade por violência no Brasil nos últimos 15 anos tem aumentado, tanto para o sexo masculino quanto para o feminino, sendo que a razão entre os sexos é aproximadamente de 12:1 (AMADOR et al., 2018).

No ano de 2012, na cidade de Itabuna - BA, o percentual de mortes por homicídio registrado entre os homens de 15 a 29 anos de idade foi 56 vezes maior que entre as mulheres, no mesmo grupo de idade (COSTA et al., 2014).

Outros estudos comparando o número de óbitos por sexo, além dos citados anteriormente, encontraram resultados semelhantes ao presente trabalho, indicando que o sexo masculino é amplamente mais afetado pelas causas externas de mortalidade. A perda prematura desses homens tem repercussões negativas na dinâmica familiar, pois estes seriam componentes importantes para a própria sustentação econômica das famílias, geralmente de baixa renda, bem como nas relações familiares gerais, como a educação dos filhos e organização das tarefas domésticas, no caso dos indivíduos casados.

\section{4 ÓBITOS POR GRAU DE ESCOLARIDADE}

$\mathrm{Na}$ avaliação do grau de escolaridade dos adultos jovens vitimados por causas externas, verificou-se que os grupos mais significativos possuíam nível fundamental incompleto e médio incompleto nos dois anos avaliados (Figuras 5 e 6 ).

Do ano de 2017 para 2018, o percentual de mortalidade no grupo com nível fundamental incompleto variou de 38,69 para $56,86 \%$. Para o grupo com nível médio incompleto, variou de 30,65 para $23,04 \%$. Esses dois grupos somados foram englobaram mais de $65 \%$ dos óbitos por causas externas nos dois anos estudados. 
Figuras 5 e 6 - Percentuais de mortalidade de adultos jovens, por causas externas, segundo a escolaridade, no município de Imperatriz - MA, nos anos de 2017 e 2018.
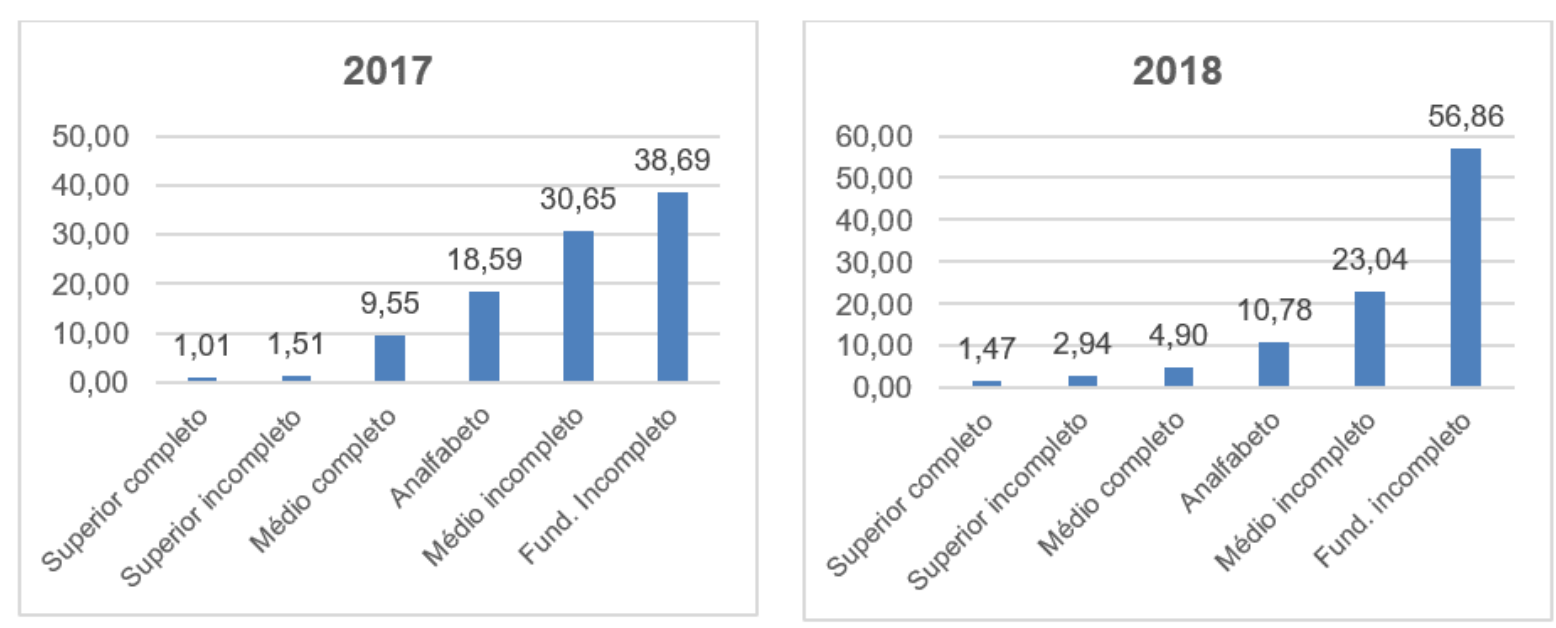

Fonte: resultado da pesquisa.

Estudo realizado em 2006 na cidade de Cuiabá - MT, identificou que a grande maioria dos óbitos por causas externas envolveu indivíduos com escolaridade entre 4 a 7 anos seguidos de 1 a 3 anos (OLIVEIRA, 2006).

A avaliação das causas externas de mortalidade no município de Teresina - PI, no período de 2001 a 2011, verificou para a variável escolaridade, que a maioria permaneceu na escola entre 4 a 7 anos (35,82\%) seguidos da escolaridade de 8 a 11 anos (22,63\%) (SOUSA et al., 2016). Estudo sobre a mortalidade por causas externas no estado do Maranhão, realizado no período de 2001 a 2010, identificou que o tempo de escolaridade mais frequente foi de 4 a 7 anos, seguido de 1 a 3 anos (LIMA et al., 2013).

Os resultados encontrados no presente estudo são semelhantes aos de trabalhos anteriores, indicando que as pessoas com menor grau de escolaridade são as principais acometidas pelas causas externas de óbitos, reforçando que indivíduos com escolaridade mais baixa estão mais sujeitos a se envolverem em eventos violentos, que muitas vezes, têm como desfecho o óbito. Esses resultados demonstram a necessidade de iniciativas para manutenção de jovens na escola como estratégia para auxiliar na proteção desses indivíduos. 


\section{5 ÓBITOS POR ETNIA}

O grupo étnico com maior número de adultos jovens vitimados por causas externas foi o dos pardos, com 77,89 e 75,98\% dos casos, respectivamente nos anos de 2017 e 2018. O grupo dos negros apresentou 15,58\% dos casos em 2017 e 14,22\% em 2018. Esses dois grupos somados representaram mais de $90 \%$ dos casos de óbitos por causas externas nos dois anos estudados (Figuras 7 e 8 ).

Figuras 7 e 8 - Percentuais de mortalidade de adultos jovens, por causas externas, segundo a etnia, no município de Imperatriz - MA, nos anos de 2017 e 2018.

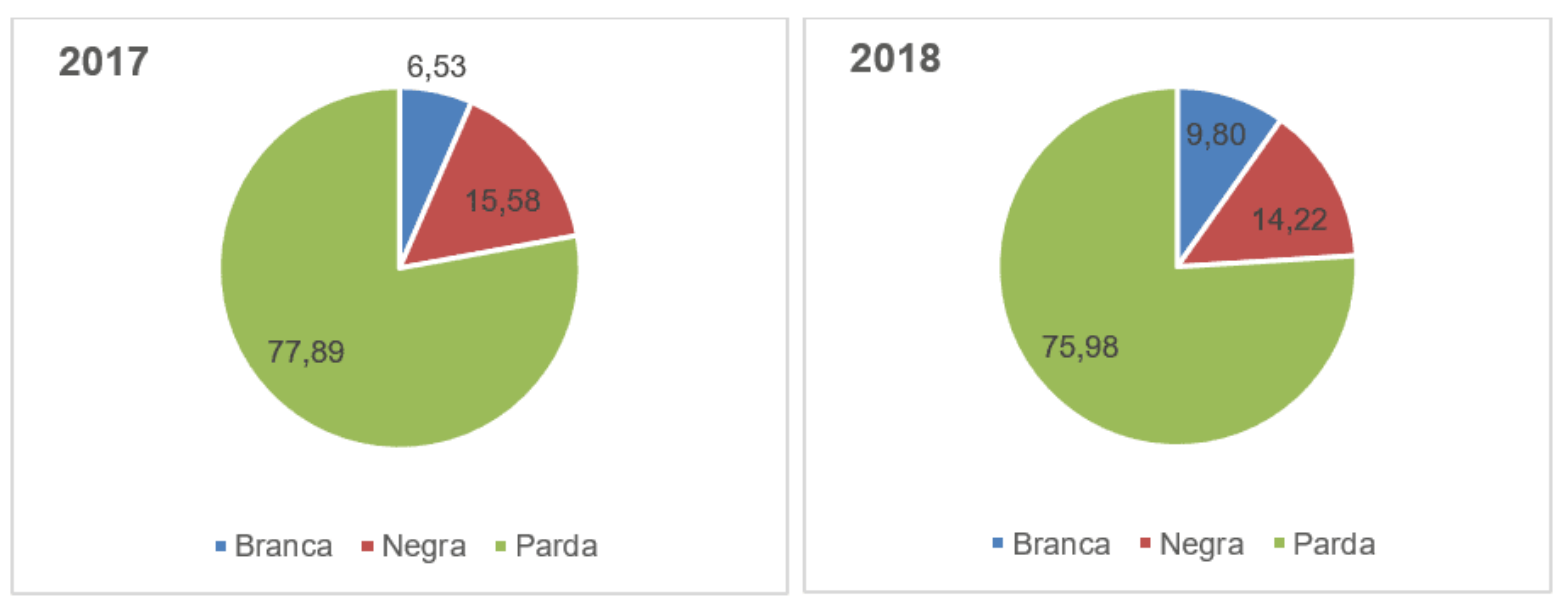

Fonte: resultado da pesquisa.

Um estudo realizado no estado da Paraíba identificou que a raça parda representou $66 \%$ dos óbitos por causas externas no ano de 2000 e 84\% no ano de 2010 (MELO; DIÓGENES, 2018).

A avaliação da mortalidade por causas externas no município de Campina Grande PB, no ano de 2015, identificou que os indivíduos do sexo masculino com um percentual de $93,97 \%$ e da cor ou raça parda com um percentual de $73,5 \%$ são os principais acometidos por essas causas (COSTA, 2016). Os resultados de mortalidade por grupo étnico são semelhantes aos encontrados em estudo no município de Teresina - PI, no período de 2001 a 2011, que verificou em relação à raça, a prevalência da parda $(70,67 \%)$ seguido da branca (12,82\%) (SOUSA et al., 2016). 
Estudo realizado na microrregião de São Mateus - ES, identificou que a mortalidade por causas externas em relação à cor da pele ou raça apresentou as maiores taxas para pardos e negros (TRISTÃO et al., 2012).

Os resultados obtidos no presente estudo são compatíveis com trabalhos anteriores realizados em outros municípios, demonstrando que os grupos étnicos pardos/negros, comumente são os mais afetados por causas externas de óbitos, representando a ampla maioria dos casos. Mesmo na cidade de Imperatriz, onde as etnias pardas/negras representam a maioria da população, os percentuais de óbitos por causas externas em indivíduos dessas etnias, são superiores aos seus percentuais na população.

\section{6 ÓBITOS POR ESTADO CIVIL}

Nos dois anos avaliados, a maior parte dos adultos jovens vítimas de causas externas foram indivíduos solteiros, correspondendo a 62,81\% em 2017 e 74,02\% em 2018, demonstrando que as causas externas atingem com uma frequência amplamente maior as pessoas desse grupo. Em seguida os indivíduos casados com 26,13 e 18,14\%, respectivamente em 2017 e 2018. Os demais grupos, individualmente ficaram abaixo de $10 \%$ nos dois anos avaliados (Figuras 9 e 10).

Figuras 9 e 10 - Percentuais de mortalidade de adultos jovens, por causas externas, segundo o estado civil, no município de Imperatriz - MA, nos anos de 2017 e 2018.
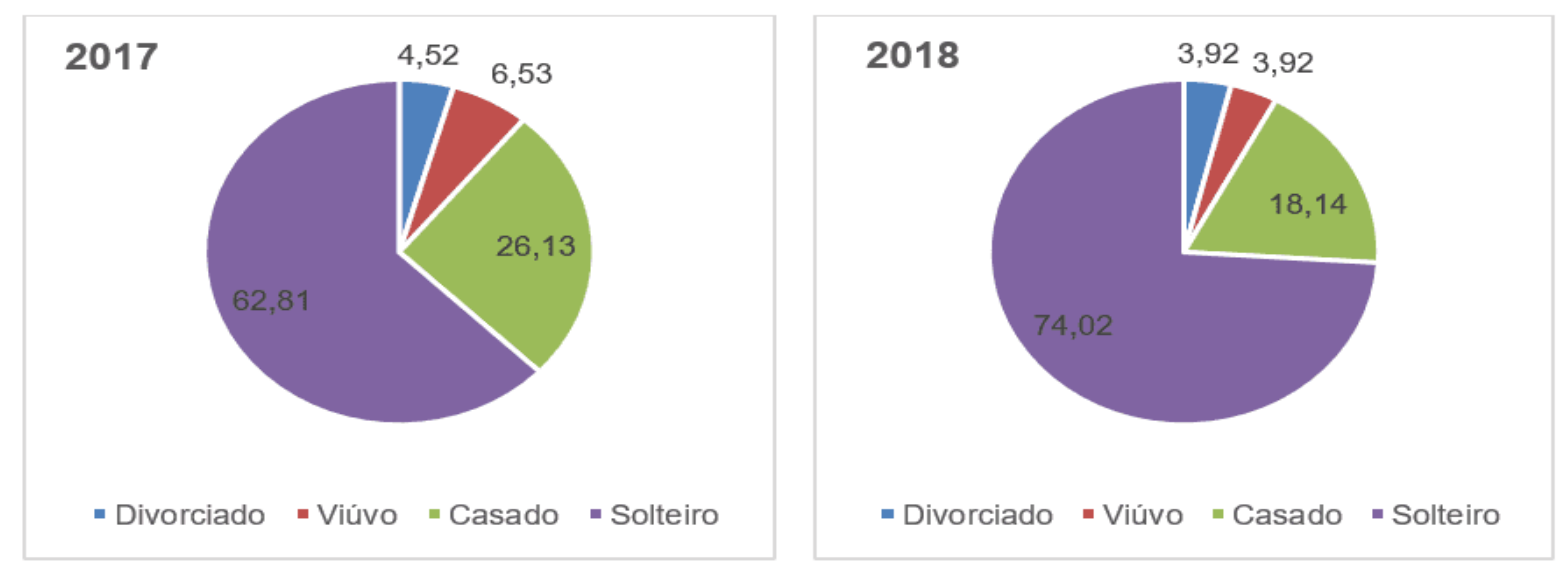

Fonte: resultado da pesquisa. 
Um estudo realizado na cidade de Teresina - PI, abrangendo o período de 2001 a 2011 , identificou que em relação ao estado civil prevaleceu solteiro $(71,74 \%)$, depois casado $(21,89 \%)$ (SOUSA et al., 2016), corroborando os resultados encontrados no presente estudo.

Na região Sul do Brasil, no período de 2004 a 2013, o estado civil das vítimas de causas externas foi de $57,81 \%$ de solteiros, $29,75 \%$ de casados, $7,08 \%$ de viúvos e $5,36 \%$ de separados judicialmente (PREIS, et al., 2018).

Os resultados encontrados no presente estudo são corroborados por outros trabalhos, evidenciando que os indivíduos solteiros são os mais afetados pelas causas externas de mortalidade. Esses resultados têm relação direta com a idade dos envolvidos, tendo em vista que a ampla maioria corresponde aos adultos jovens, conforme resultados de outros estudos, além dos obtidos no presente trabalho.

\section{CONCLUSÕES}

- As três principais causas externas de óbitos, nos anos de 2017 e 2018, foram respectivamente: 1) agressão por arma de fogo; 2) acidente de trânsito e 3) agressão por instrumento perfurocortante.

- Com relação à idade, o grupo dos adultos jovens foi o que apresentou maior mortalidade por causas externas, representando mais da metade de todos os óbitos por essas causas, nos dois anos avaliados.

- Com relação ao gênero, nos dois anos avaliados, os indivíduos do sexo masculino representaram a ampla maioria dos óbitos por causas externas.

- Na avaliação da escolaridade, verificou-se que as maiores taxas de óbito por causas externas ocorreram com pessoas que possuíam nível fundamental incompleto, seguidas daquelas com médio incompleto nos dois anos avaliados.

- Na avaliação da etnia, verificou-se que os indivíduos pardos e negros somados, representaram a maioria dos casos de óbitos por causas externas nos dois anos estudados.

- Na avaliação do estado civil, verificou-se que nos dois anos avaliados, a maior parte das vítimas de causas externas foram indivíduos solteiros. 
- As principais vítimas de causas externas foram adultos jovens, do sexo masculino com baixo grau de escolaridade, pardos e solteiros.

\section{REFERÊNCIAS}

AMADOR, Ana Edimilda. MARQUES, Marilane Vilela. SOUZA, Marta Rovery de. SOUZA, Dyego Leandro Bezerra de. BARBOSA, Ribeiro Barbosa. Mortalidade de jovens por violência no brasil: desigualdade espacial e socioeconômica. Revista Brasileira em Promoção da Saúde, Fortaleza: 31(3): 1-9, jul./set., 2018.

BATISTA, Josemar. BARRETO, Mayckel da Silva. MERINO, Maria de Fatima Garcia Lopes. FRACASSO, Nathalia Vasconcelos. BALDISSERA, Vanessa Denardi Antoniassi. Perfil Epidemiológico da Mortalidade por Causas Externas Entre Beneficiários de Planos de Saúde no Brasil. Revista de Enfermagem do Centrooeste Mineiro. São João del-Rei: 2018;8:e1870. Disponível em: https://doi.org/10.19175/recom.v7i0.1870. Acesso em: 12/02/2020

BRASIL. Ministério da Saúde. Acidentes e Violências. Brasília: 2017. Disponível em: https://www.saude.gov.br/saude-de-a-z/acidentes-e-violencias. Acesso em 18/02/2020.

BRASIL. Ministério da Saúde. Secretaria de Vigilância em Saúde. Departamento de Vigilância de Doenças e Agravos Não Transmissíveis e Promoção da Saúde. Saúde Brasil 2014: uma análise da situação de saúde e das causas externas / Ministério da Saúde, Secretaria de Vigilância em Saúde, Departamento de Vigilância de Doenças e Agravos Não Transmissíveis e Promoção da Saúde. Brasília: Ministério da Saúde, 2015. 462 p.: il.

CAVALCANTI, Alessandro Leite. MONTEIRO, Bárbara Vanessa. Mortalidade por causas externas em adultos no município de Campina Grande, Paraíba, Brasil. Scientia Médica, Porto Alegre: v. 18, n. 4, p. 160-165, out./dez. 2008.

CORASSA, Rafael Bello. FALCI, Denise Mourão. GONTIJO, Cristina Franco. MACHADO, Geralda Vanessa Campos. ALVES, Paula Aryane Brito. Evolução da 
mortalidade por causas externas em Diamantina (MG), 2001 a 2012. Caderno Saúde Coletiva, Rio de Janeiro: 25 (3): 302-314, 2017.

COSTA, Andréa Ramalho. Estudo da mortalidade por causas externas no município de Campina Grande. Trabalho de Conclusão de Curso (Bacharelado em Direito) - Centro de Ciências Jurídicas. Universidade Estadual da Paraíba, Campina Grande: 2016. 37f. il.

COSTA, Flávia Azevedo de Mattos Moura. TRINDADE; Ruth França Cizino da. SANTOS, Claudia Benedita dos. Mortes por homicídios: série histórica. Revista Latino-Americana de Enfermagem [online]. nov.-dez. 2014; 22(6): 1017-1025. Disponível em: < http://dx.doi.org/10.1590/0104-1169.3603.2511 >. Acesso em 11/02/2020.

COSTA, Juvenal Soares Dias da. GIRALDI, Michel Cerioli. CARRET, Maria Laura Vidal. FERREIRA, Ana Maria Teixeira Borges. STRAUCH, Eliane Schneider. MORAES, Maurício. Evolução da mortalidade por causas externas no município de Pelotas e no Estado do Rio Grande do Sul, Brasil, 1996-2009. Epidemiologia e Serviços de Saúde, Brasília: v.22 n.2 jun. 2013.

DANTAS, Thiago de Medeiros. Mortalidade segundo sua causa de morte e seus determinantes: uma análise para as capitais brasileiras e municípios do nordeste do Brasil, 2000 e 2010. Natal: 2014. 80 f.: il.

GONSAGA, Ricardo Alessandro Teixeira. RIMOLI, Caroline Fernandes. PIRES, Eduardo Araújo. ZOGHEIB, Fernando Scaramucci. FUJINO, Marcos Vinicius Tadao. CUNHA, Milena Bolini. Evaluation of the mortality due to external causes. Rev. Col. Bras. Cir. Rio de Janeiro: vol.39 no.4 July/Aug. 2012.

IBGE - INSTITUTO BRASILEIRO DE GEOGRAFIA E ESTATÍSTICA. Estimativa de população, 2018. Rio de Janeiro: IBGE, 2018. Disponível em: < $\mathrm{ftp}: / / \mathrm{ftp}$. ibge.gov.br/Estimativas_de_Populacao/Estimativas_2018/estimativa_TCU_2 018_20181108.pdf >. Acesso em 11/11/2019. 
IBGE - INSTITUTO BRASILEIRO DE GEOGRAFIA E ESTATÍSTICA. Indicadores sociodemográficos e de saúde no Brasil. Rio de Janeiro: IBGE, 2009.

LIMA, Rômulo Henrique da Silva. AMORIM, Rayane Trindade. MARTINS, Vicenilma de Andrade. RODRIGUES, Lívia dos Santos. BATISTA, Rosângela Fernandes Lucena. Mortalidade por causas externas no estado do Maranhão, Brasil: tendências de 2001 a 2010. Revista Pesquisa Saúde, São Luiz: 14(2): 96-100, maioago, 2013.

MATOS, Karla Fonseca de. MARTINS, Christine Baccarat de Godoy. Mortalidade por causas externas em crianças, adolescentes e jovens: uma revisão bibliográfica. Espaç. saúde (Online). Londrina: v. 14, n. 1 e 2, p. 82-93, 2013.

MELO, Kallyne de Oliveira Cabral. DIÓGENES, Victor Hugo Dias. Mortalidade por causas externas e seus diferenciais: uma análise para as mesorregiões do estado da paraíba, 1980 a 2010. Revista Científica Multidisciplinar Núcleo do Conhecimento. São Paulo: ano 03, ed. 11, vol. 03, pp. 118-136 nov. 2018.

OLIVEIRA, Juliana da Silva. CONSTÂNCIO, Tatiane Oliveira de Souza. SANTOS, Isleide Santana Cardoso. NERY, Adriana Alves. Óbitos por causas externas relacionadas ao trabalho. Rev. enferm. UFPE online. 2019;13: e237870 Disponível em: < https://doi.org/10.5205/1981-8963.2019.237870 > Acesso em: 11/02/2020.

OLIVEIRA, Ligia Regina de. Subsídios para a implantação de um sistema de vigilância de causas externas no município de Cuiabá - Mato Grosso. [Tese]. São Paulo: Universidade de São Paulo; Faculdade de Saúde Pública; 2006. 299 p.

PALMEIRA, Cátia. FELIX, Jogasil da Silva. GUIMARÃES, Marivalda da Silva. ARÁUJO, Robson Silva. Morte por causas externas em adolescentes na cidade de Salvador. 61ํㅡㄹ Congresso Brasileiro de Enfermagem, 2009. Disponível em: < http://www.abeneventos.com.br/anais_61cben/files/02408.pdf >.. Acesso em: 10/02/2020. 
PREIS, Lucas Corrêa. LESSA, Greice. TOURINHO, Francis Solange Vieira SANTOS, José Luís Guedes dos. Epidemiologia da mortalidade por causas externas no período de 2004 a 2013. Revista enfermagem UFPE on line., Recife: 12(3):716-28, mar., 2018. Disponível em: < https://doi.org/10.5205/1981-8963-v12i3a230886p716728-2018 >. Acesso em: 03/11/2019.

REICHENHEIM, Michael Eduardo. SOUZA, Edinilsa Ramos de. MORAES, Claudia Leite. JORGE, Maria Helena Prado de Mello. SILVA, Cosme Marcelo Furtado Passos da. MINAYO, Maria Cecília de Souza Violência e lesões no Brasil: efeitos, avanços alcançados e desafios futuros. The Lancet, London: p. 75-89, 2011. Disponível em: $<$ http://download.thelancet.com/flatcontentassets/pdfs/brazil/brazilpor5.pdf > Acesso em: 10/02/2020.

SETTERVALL, Cristina Helena Costanti. DOMINGUES, Cristiane de Alencar. SOUSA, Regina Marcia Cardoso de. NOGUEIRA, Lilia de Souza. Mortes evitáveis em vítimas com traumatismos. Rev. Saúde Pública [online]. vol.46, n.2, pp.367-375, 2012. Disponível em: < https://doi.org/10.1590/S0034-89102012005000010 > Acesso em: 10/02/2020.

SILVA, Marta Angélica lossi. PAN, Raquel. MELO, Ludimila. BORTOLI, Paula Saud de. NASCIMENTO, Lucila Castanheira. Perfil dos atendimentos a crianças e adolescentes vítimas de causas externas de morbimortalidade, 2000-2006. Rev. Gaúcha Enferm. (online) vol.31 no.2 Porto Alegre: jun. 2010. Disponível em: <https://doi.org/10.1590/S1983-14472010000200021 > Acesso em: 08/02/2020

SOUSA, Andressa Suelly Batista de. SILVA, Samanta Calisto da. CAVALCANTE, Milena France Alves. Mortalidade por causas externas em adultos jovens em Teresina-PI no período de 2001-2011. Revista Interdisciplinar. Teresina: v. 9, n. 1, p. 57-65, jan. fev. mar. 2016.

SOUZA, Maria de Fátima Marinho de. MALTA, Deborah Carvalho. CONCEIÇÃO, Gleice Margarete de Souza. SILVA, Marta Maria Alves da. GAZAL-CARVALHO, Cynthia. MORAIS NETO, Otaliba Libânio de. Análise descritiva e tendência de 
acidentes de transporte terrestre para políticas sociais no Brasil. Epidemiol. Serv. Saúde. Brasília: 2007; 16(1). 33-44.

TREVISOL, Fabiana Schuelter. CUSTÓDIO, Geisiane. LOCKS, Luiz Henrique. TREVISOL, Daisson José. Avaliação das mortes por causas externas na cidade de Tubarão (SC) no ano de 2009.Rev. AMRIGS. Porto Alegre: 55(1): 25-30, jan.-abr. 2011. tab. ilus.

TRISTÃO, Kamila Medani. LEITE, Franciéle Marabotti Costa. SCHMILDT, Edilson Romais. LEITE, Esmeraldo Costa. CASTRO, Denise Silveira de. VILELA, Ana Paula Martins. Mortalidade por causas externas na microrregião de São Mateus, estado do Espírito Santo, Brasil: tendências de 1999 a 2008. Epidemiol. Serv. Saúde. Brasília: v.21 n.2 jun. 2012.

WAISELFISZ, Julio Jacobo. Mapa da Violência 2013: Mortes por armas de fogo. Centro Brasileiro de Estudos Latino-americanos. Brasília: Instituto Sagary; 2013.

Enviado: Agosto, 2020.

Aprovado: Setembro, 2020. 